\title{
Tobacco Rotated with Rapeseed for Soil-Borne Phytophthora Pathogen Biocontrol: Mediated by Rapeseed Root Exudates
}

\begin{abstract}
Yuting Fang ${ }^{1,2 \dagger}$, Limeng Zhang ${ }^{3 \dagger}$, Yongge Jiao ${ }^{3+}$, Jingjing Liao 1,2, Lifen Luo ${ }^{1,2}$, Sigui Ji ${ }^{3}$, Jiangzhou $\mathrm{Li}^{3}$, Kuai Dai ${ }^{3}$, Shusheng Zhu ${ }^{1,2 *}$ and Min Yang ${ }^{1,2 *}$
\end{abstract}

'State Key Laboratory for Conservation and Utilization of Bio-Resources in Yunnan, Yunnan Agricultural University, Kunming, China, ${ }^{2}$ Key Laboratory for Agro-biodiversity and Pest Control of Ministry of Education, Yunnan Agricultural University, Kunming, China, ${ }^{3}$ Yunnan Tobacco Company, Yuxi Branch, Yuxi, China

Black shank, caused by Phytophthora parasitica var. nicotianae, is a widespread and destructive disease of tobacco. Crop rotation is essential in controlling black shank. Here, we confirmed that rotating black shank-infested fields with rapeseed (Brassica napus) suppressed the incidence this disease. Further study demonstrated that rapeseed roots have a strong ability to attract zoospores and subsequently stop the swimming of zoospores into cystospores. Then, rapeseed roots secrete a series of antimicrobial compounds, including 2-butenoic acid, benzothiazole, 2(methylthio)benzothiazole, 1-(4-ethylphenyl)-ethanone, and 4-methoxyindole, to inhibit the cystospore germination and mycelial growth of $P$. parasitica var. nicotianae. Thus, rapeseed rotated with tobacco suppresses tobacco black shank disease through the chemical weapons secreted by rapeseed roots.

Keywords: Phytophthora parasitica, root exudates, chemical interaction, soil-borne pathogen, rotation

\section{INTRODUCTION}

Black shank, caused by Phytophthora parasitica var. nicotianae, is a destructive disease of tobacco (Nicotiana tabacum L.), with losses in individual fields reaching 100\% (Gallup et al., 2006; Sun et al., 2011). P. parasitica var. nicotianae is one type of soil-borne pathogen that is difficult to control due to its ability to survive in the soil for many years, even in the absence of tobacco (Erwin and Ribeiro, 1996; Gallup et al., 2006; Sun et al., 2011). Although the use of resistant cultivars, fungicides, and other cultural methods have been recommended to control black shank disease, few of these control measures are sufficiently effective, practical, or economical (Kong et al., 1995; Gallup et al., 2006). Once a soil becomes heavily infested with $P$. parasitica var. nicotianae, even the most resistant varieties may be damaged (Kong et al., 1995; Gallup et al., 2006; Sun et al., 2011).

Crop rotation may be the best, most widely practiced, and most cost-effective method for reducing black shank disease and improving tobacco productivity (Gallup et al., 2006; Li et al., 2006; Zhang et al., 2015). Crop rotations can increase soil fertility, soil tilth and aggregate stability; improve soil water management; and reduce erosion and the build-up of soil-borne plant pathogens (Larkin et al., 2010). Previous studies have shown that the rotation of Gramineae, Brassica, and Allium crops with tobacco successfully suppressed black shank disease of tobacco (Sullivan et al., 2005; Gallup et al., 2006; Zhang et al., 2015). In particular, Brassica crops have been the most consistent and effective rotation crops for reducing soil-borne diseases, which infected by Fusarium spp., Sclerotium spp., Rhizoctonia spp., Streptomyces spp (Brown and Morra, 1997; 
Smolinska and Horbowicz, 1999; Matthiessen and Kirkegaard, 2006; Larkin and Griffin, 2007; Larkin, 2008; Larkin et al., 2010) and improving soil characteristics and crop yield (McGuire, 2003). Current production practices in many tobacco production areas of southern China are also based on rotation with rapeseed (Brassica napus L.) to control diseases and increase the yield of tobacco (Li et al., 2006). In this area, tobacco is grown from April to October, and rapeseed is subsequently grown from October to March of the next year. Such rotations with rapeseed have been observed to reduce the incidence or severity of some soil-borne tobacco diseases, including black shank ( $P$. parasitica var. nicotianae), black root rot (Thielaviopsis basicola), and brown spot (Alternaria alternata), relative to continuous tobacco planting (Li et al., 2006).

Reportedly, crop rotation can help reduce soil-borne pathogens by interrupting the host-pathogen cycle, inhibiting pathogen growth directly, or altering the soil characteristics (Kheyrodin, 2011; Ratnadass et al., 2012; Larkin, 2015). Many studies have investigated the mechanism of soil-borne disease suppression by Brassica crops, mainly focusing on biofumigation of green biomass through the production of toxic sulfur metabolites (such as isothiocyanates) and the alteration of soil microbial communities (Sarwar et al., 1998; Mazzola et al., 2001; Cohen et al., 2005; Larkin and Griffin, 2007). However, rapeseed plants grow in the field for approximately 5 months, and the biomass does not totally get incorporated into the soil after harvest in South China. Thus, rapeseed rotated with tobacco for soil-borne disease suppression maybe mainly due to the secretion of antimicrobial substances by rapeseed roots. Plant roots can continuously produce and secrete many compounds into the rhizosphere to mediate the interactions between the roots and pathogens (Bais et al., 2006; Yang et al., 2014). Pathogens can recognize the signals in the root exudates to colonize the host plant (Bais et al., 2004). Plant roots can also secrete a number of substances to protect themselves against pathogen and non-host pathogen infection (Bais et al., 2004, 2006). Thus, it is interesting to investigate whether rapeseed plants growing in the soil can secrete root exudates to help tobacco plants suppress soil-borne diseases.

Here, we aim to: (i) confirm the phenomena of tobacco black shank suppression in a four-year rotation field study with tobacco and rapeseed, (ii) observe the interaction between roots and zoospores, and (iii) determine the mechanisms involved in soilborne Phytophthora disease suppression in tobacco, including the antimicrobial compounds identification in rapeseed root exudates and their antimicrobial activity assessment.

\section{MATERIALS AND METHODS}

\section{Field Experiment with Rapeseed and Tobacco Rotation for $P$. nicotianae Suppression}

The field rotation study was carried out at the Zhao Wei base of scientific research in Yuxi city $\left(24.497^{\circ} \mathrm{N}, 24.317^{\circ} \mathrm{E}\right)$ from 2012 through 2015 to examine the effect that rapeseed and tobacco rotation have on the disease severity of black shank disease in tobacco. The field selected for the study was heavily infested with black shank and contained sandy loam soil. The experiment included two treatments. One treatment involved the rotation of tobacco and rapeseed in which tobacco (cv. KRK26) was grown from May to October and rapeseed (cv. YHY-2) was subsequently grown from October to April of the next year. The other treatment involved continuous tobacco (cv. KRK26) cropping, in which only tobacco was grown from April to October. Each treatment contained three plots $\left(200 \mathrm{~m}^{2}\right)$ arranged in the same field using a completely randomized block design. The KRK26 tobacco variety, which is susceptible to $P$. parasitica var. nicotianae, was used in this study. During the first week of May each year, healthy greenhouse-grown seedlings with nine leaves were purchased from a market and transplanted in the field. The tobacco plants were planted $0.5 \mathrm{~m}$ apart in a row and $1.1 \mathrm{~m}$ between rows. Rapeseed variety YHY-2 was used for rotation. The rapeseed plants were transplanted at the seedling age of 3035 days in October, with a density of 10,000 seedlings/ha. The field management with respect to water, fertilizers, weed control, and insect pest control was uniform for each plot based on the recommendations set forth in the tobacco production guide of Yunnan. The diseased plants with the symptoms of black shank were counted in each plot at the mature stage. Disease incidence $=$ (The number of diseased plants with black shank symptoms in each plot $\div$ The total number of plants in each plot $) \times 100 \%$. Yield data were collected for all plots throughout the four-year period of the experiment. The actual yield per plot was determined as the dry leaf weight of tobacco.

\section{Effect of Rapeseed Roots on Zoospore Swimming and Cystospore Formation and Germination}

Isolate of $P$. parasitica var. nicotianae (YXCJ-1, Genbank accession number: KX268718) was collected from tobacco plants with typical symptoms of black shank. YXCJ-1 was grown on carrot agar (CA) medium, and zoospores were produced as described previously (Morris and Ward, 1992). A modified capillary root model, as described by Yang et al. (2014), was used to monitor the interaction of roots and zoospores. Briefly, a capillary tube (1 mm external diameter) was bent into a U-shape, placed on a glass slide and overlaid with a coverslip to form a chamber with one open side. The primary roots of rapeseed (cv. YHY-2) plants were excised with a sterile razor blade, and the root tip was inserted into the open end of the chamber; zoospore suspensions $\left(1 \times 10^{4}\right.$ zoospores $\left./ \mathrm{mL}\right)$ were then added into the chamber. The slides were incubated in a humid petri dish at room temperature. The behavior of zoospores on the root tip and hair zone was recorded every $5 \mathrm{~min}$ for a period of $120 \mathrm{~min}$ using a video camera attached to a compound microscope (Leica DM2000, Wetzlar, Germany). A capillary tube was inserted into a chamber with the same zoospore suspension as a control. The number of zoospores and cystospores on the different root zones were counted on the photographs from 5 to $25 \mathrm{~min}$. The 
chemotactic ratio (CR) was determined following the formula described by Muehlstein et al. (1988), where CR = (scores of zoospores and cystospores on the test root)/(score of zoospores and cystospores on the control). Positive CR values indicate positive chemotaxis. The number of germinated and ruptured cystospores as well as the growth direction of the germ tube was recorded on the photographs from 30 to $120 \mathrm{~min}$. The experiment was repeated three times, and six roots were tested per run.

\section{Root Exudates Collection and Identification \\ Root Exudates Collection}

Root exudates of rapeseed (cv. YHY-2) were collected by a previously described trapping system with a few modifications (Yang et al., 2014). Briefly, rapeseed seeds were sterilized with $6 \% \mathrm{H}_{2} \mathrm{O}_{2}$ (Sigma-Aldrich Co., Beijing, China) for $8 \mathrm{~min}$ and sowed into washed silica sand in glass pots $(2 \mathrm{~L}$ of sand per pot). Three seeds were sowed into each pot in a greenhouse and irrigated with 0.1-strength Hoagland solution at a rate of $10 \mathrm{~mL} /$ day. Additional distilled $\mathrm{H}_{2} \mathrm{O}$ was supplied as needed. When the rapeseed plants reached the six-leaf stage, each pot was washed with $2 \mathrm{~L}$ of distilled $\mathrm{H}_{2} \mathrm{O}$. A column filled with Amberlite XAD-4 resin (Sigma-Aldrich Co., Beijing, China) and fitted with a circulating attachment was then connected to the trapping systems. The solution was circulated at a rate of $1 \mathrm{~L} / \mathrm{h}$ by airlifting. The root exudates from each column were collected in separate columns, with nine columns in total. The column was detached after 7 days, washed with 10-bed volumes of distilled $\mathrm{H}_{2} \mathrm{O}$, and then eluted with $200 \mathrm{~mL}$ of highperformance liquid chromatography (HPLC) grade methanol (Fisher Scientific, Shanghai) followed by $100 \mathrm{~mL}$ of HPLC grade dichloromethane (Fisher Scientific, Shanghai). Eluates from three columns were pooled into one bottle, filtered and concentrated under reduced pressure. The concentrate was dissolved into $1 \mathrm{~mL}$ of methanol for further analysis. Control pots without rapeseed plants were treated identically.

\section{Gas Chromatography-Mass Spectrometry (GC-MS) Analyses of Root Exudates}

The GC-MS fingerprints of the root exudates were obtained on an Agilent 7890-5975 instrument (Agilent, USA). The root exudates were dried under nitrogen gas, followed by methoximation (Sigma-Aldrich Co., Beijing) and trimethylsilylation (Sigma-Aldrich Co., Beijing) derivatization as described by $\mathrm{Xu}$ et al. (2012). The root exudates were separated on an HP-5 MS capillary column (19091S-433, 30 $\mathrm{m} \times 0.25 \mathrm{~mm} \times 0.25 \mu \mathrm{m}$, Agilent). The injection volume was $1 \mu \mathrm{L}$ in the splitless mode, and the injector temperature was $260^{\circ} \mathrm{C}$. The initial column temperature was $40^{\circ} \mathrm{C}$ (held $2 \mathrm{~min}$ ) and programmed to increase at a rate of $5^{\circ} \mathrm{C} / \mathrm{min}$ to $250^{\circ} \mathrm{C}$, where it was then held for $10 \mathrm{~min}$. The transfer line temperature was $280^{\circ} \mathrm{C}$. Helium (99.999\% purity) was used as the carrier gas at a flow rate of $1 \mathrm{~mL} / \mathrm{min}$. Mass spectra were obtained in electron impact (EI) ionization mode at $70 \mathrm{eV}$ by monitoring the full-scan range $(\mathrm{m} / z 50-550)$. The compounds were identified by matching the mass spectra obtained with those of the reference compounds stored in the Wiely7n.1 Library. Components with more than an $80 \%$ similarity were regarded as undoubtedly existing in the root exudates. The collection from the control pot was analyzed under similar conditions. The components that appeared in the control treatment were not recorded in the final result.

\section{High-Performance Liquid Chromatography (HPLC) Analysis of Root Exudates}

The standards of 17 putative compounds identified by GC-MS were purchased from the Guizhou Dida Biological Technology Co. for antimicrobial activity analysis and then eight compounds with antimicrobial activity (Supplementary Table S1) were further selected to determine their concentration in the rapeseed root exudates by HPLC on an Agilent 1260 Infinity instrument (Agilent, USA). The HPLC separations were performed on an Kinetex-C18 column $(4.6 \times 100 \mathrm{~mm}, 2.6 \mathrm{u})$ (Phenomenex, Guangzhou) with the following solvent system: solvent A = HPLC grade methanol (Fisher Scientific, Shanghai) and solvent $\mathrm{B}=10 \%$ methanol and $0.1 \%$ phosphoric acid HPLC grade (Sigma-Aldrich Co., Beijing) in HPLC grade water (Fisher Scientific, Shanghai). A multistep gradient was used for all separations with an initial injection volume of $10 \mu \mathrm{L}$ and a flow rate of $0.5 \mathrm{~mL} / \mathrm{min}$. The multistep solvent gradient was as follows: $0-7 \mathrm{~min}$ consisted of $22-58 \%(\mathrm{v} / \mathrm{v})$ solution A, 7-20 min consisted of $58-95 \%(\mathrm{v} / \mathrm{v})$ solution A, and 2025 min consisted of isocratic conditions of $95 \%$ solution A. The column temperature was maintained at $30^{\circ} \mathrm{C}$. Chromatograms were recorded at 210 and $254 \mathrm{~nm}$, and the retention times of the target compounds were established from standards. The compounds in the samples were identified by comparing the results to authentic standards. The concentrations of the target compounds in the samples were quantified using standard curves that showed the linear relationships between the peak areas and the concentrations.

\section{Inhibition of $P$. parasitica var. nicotianae by Rapeseed Root Exudates and Pure Compounds}

The inhibitory activity of the root exudates and target compounds on the mycelial growth of $P$. parasitica var. nicotianae was determined according to a previously published method (Zhu et al., 2007). Briefly, a fresh plug (5 mm in diameter) was removed from the growing edge of a CA medium culture and transferred onto CA medium supplemented with the root exudates $(0$, $0.2,0.4,0.6,0.8$, and $1.0 \mathrm{mg} / \mathrm{mL}$ ) or target compounds. All tested compounds were purchased from the Guizhou Dida Biological Technology Co. (Supplementary Table S1) and were each dissolved in methanol (Fisher Scientific, Shanghai) to prepare stock solutions, which were diluted in distilled water to the test concentrations. The concentrations of all target compounds in the CA medium are listed in Supplementary Table S1. The antimicrobial activity of target compounds were preliminary assessed on CA medium amended with compound at concentration of $0,400,600,800$, and $1000 \mathrm{mg} / \mathrm{L}$. If the compound showed significant antimicrobial activities, the 
concentrations, which inhibit the mycelial growth of $P$. parasitica var. nicotianae from 10 to $90 \%$, were further determined. In all cases, the final amount of solvent never exceeded $1 \%$ (vol/vol) in the treated and control samples. Mycelial growth was assessed by measuring the colony diameter after dark incubation at $25^{\circ} \mathrm{C}$ for 4 days.

The inhibitory activity of the root exudates and target compounds against the zoospore motility and cystospore germination was measured according to a published procedure with slight modifications (Yang et al., 2014). Briefly, an aliquot of $40 \mu \mathrm{L}$ of a target compound solution was added to depression glass slides. Then, $40 \mu \mathrm{L}$ of a zoospore suspension $\left(1 \times 10^{5}\right.$ zoospores $\left./ \mathrm{mL}\right)$ or cystospore suspension $\left(1 \times 10^{5}\right.$ cystospores $\left./ \mathrm{mL}\right)$ was added immediately to the glass slides containing each respective solution. The slides were placed in Petri dishes containing moist filter paper and incubated in the dark at $24^{\circ} \mathrm{C}$. The percentage of zoospores encysted into cystospores was recorded under the microscope after zoospore incubation for $20 \mathrm{~min}$. The number of germinated cystospores was counted under a microscope after cystospore incubation for $4 \mathrm{~h}$. The experiment was conducted three times, each time in triplicate.

The inhibition of mycelial growth, zoospore motility and cystospore germination by the root exudates or target compounds was calculated (Zhu et al., 2007). The inhibition rate $(\%)=100 \% \times\left(D_{\text {control }}-D_{\text {treated }}\right) / D_{\text {control }}$, in which $D_{\text {control }}$ is the expansion diameter of mycelia on media without compound $(0 \mathrm{mg} / \mathrm{mL}), D_{\text {treated }}$ is the expansion diameter of mycelia on the

A

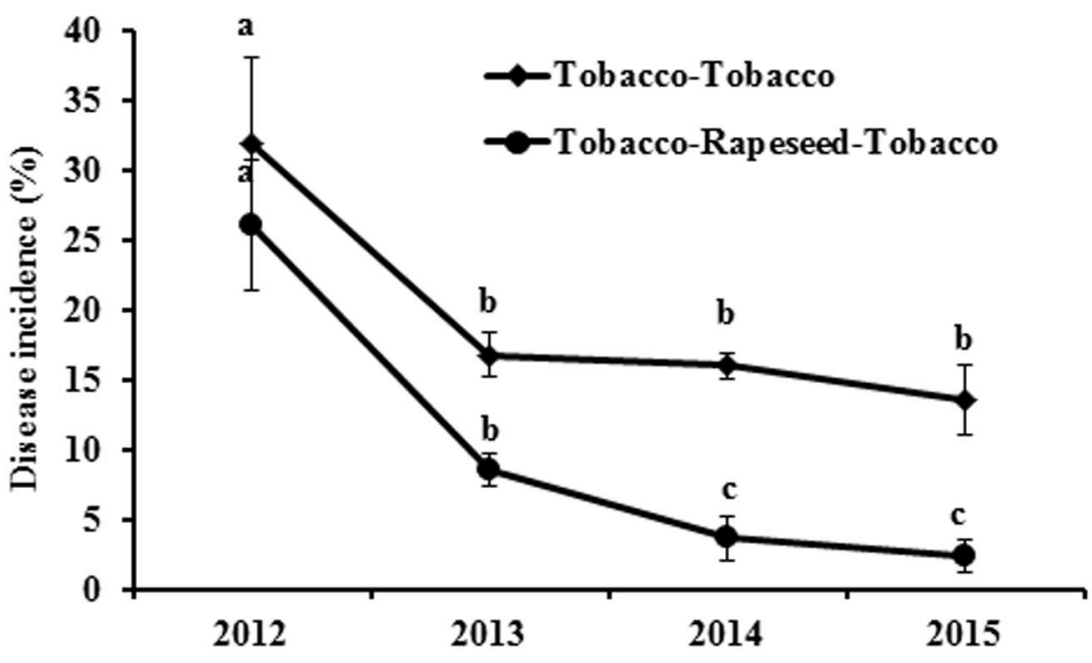

B

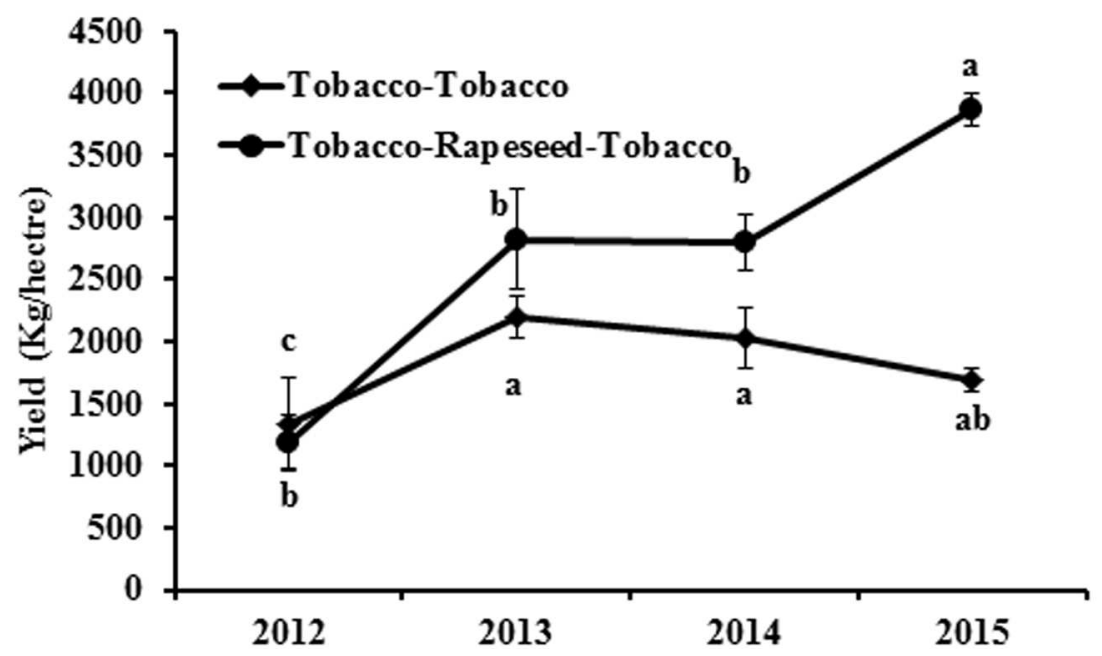

FIGURE 1 | Effect of rapeseed and tobacco rotation on black shank disease in tobacco and tobacco yield from 2012 through 2015. (A,B) Show the black shank disease incidence and the leaf yield in continuous tobacco cropping fields or in tobacco and rapeseed rotation fields, respectively. Bars represent the means \pm SE. Bars with different letters are significantly different $(p<0.05)$. 
media amended with different concentrations of compounds. The median effective concentration value $\left(\mathrm{EC}_{50}\right)$ for each isolate was calculated by regressing the percentage of growth inhibition against the logarithm value of the fungicide concentration using the software Microsoft Excel 2003.

\section{Data Analysis}

All data from the different treatments were evaluated by oneway analysis of variance (ANOVA) followed by Fisher's least significant difference (LSD) test $(p<0.05)$ with PASW Statistics 18 (SPSS Inc., Chicago, IL, USA).

\section{RESULTS}

\section{Rapeseed and Tobacco Rotation Suppressed Black Shank in Tobacco}

The disease incidence of black shank in the field ranged from 25 to $35 \%$ in 2012 (Figure 1A). After rotation with rapeseed, the disease incidences significantly decreased compared with the continuous tobacco cropping (Figure 1A). Although the disease incidences all decreased in both treatments in 2013, the decreased rate in rapeseed rotation treatment reached $67.47 \%$, which higher than $47.41 \%$ in continuous tobacco cropping treatment. Notably, the disease incidence gradually decreased with an increased rotation time from 2012 to 2015 (Figure 1A). The yield of tobacco also increased $128.8 \%$ after rotation with rapeseed compared with the continuous tobacco cropping (Figure 1B).

\section{Rapeseed Roots Interfere with the Behavior and Development of Zoospores}

The zoospores exhibited strong chemotaxis towards the rapeseed roots and then attached to the surfaces of the root tips (Figures 2A-C) and the root hair zone (Figure 2E) but did not exhibit chemotaxis towards the capillary tube (Figure 2D). The CR also indicated that the zoospores exhibited positive chemotaxis toward the rapeseed roots (Supplementary Table S2),

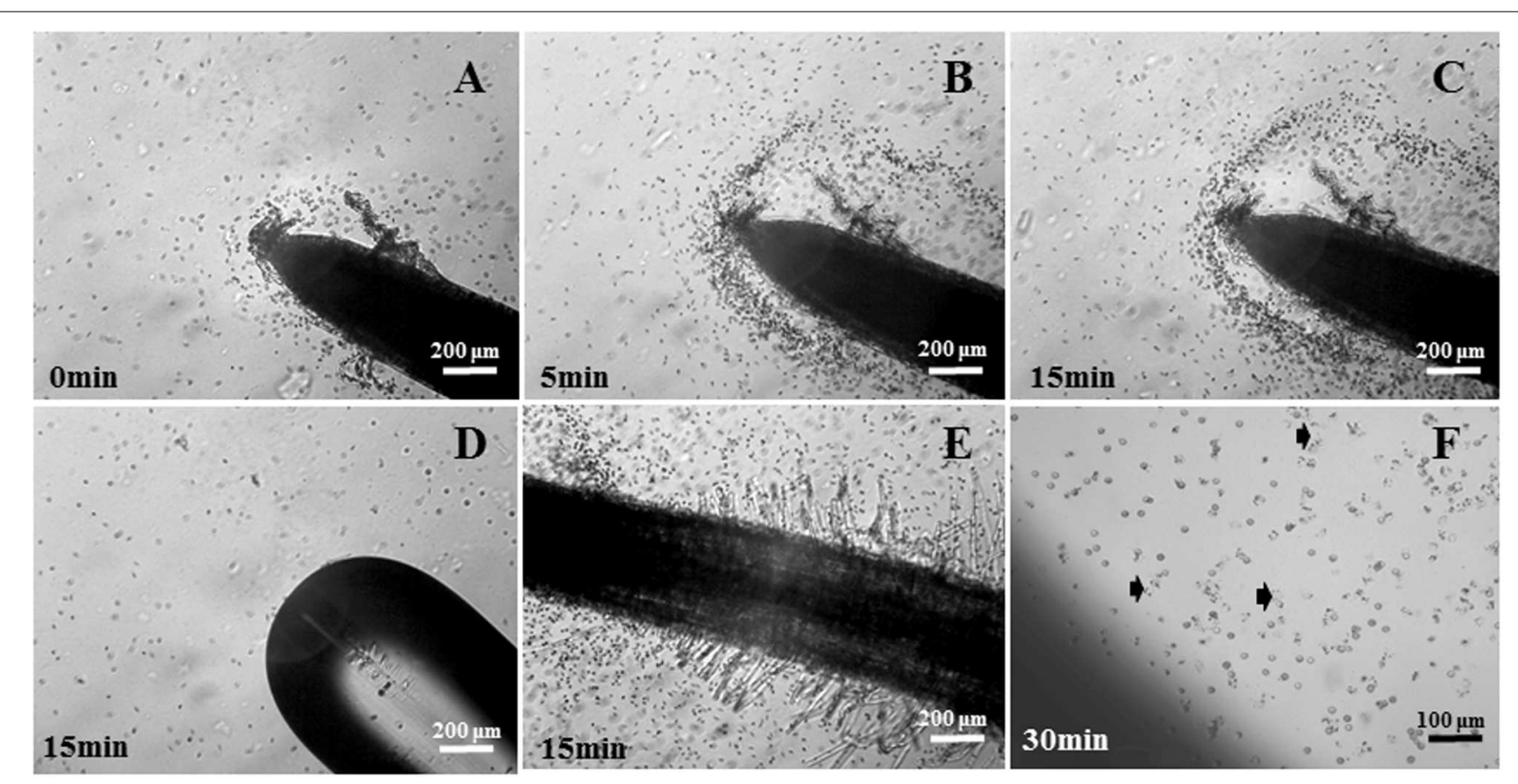

FIGURE 2 | Interaction analysis of rapeseed roots with zoospores of Phytophthora parasitica var. nicotianae. (A-C) Spores were attracted by rapeseed root and clustered in the rhizosphere from 0 to $15 \mathrm{~min}$. (D) The chemotactic ability of zoospores towards the capillary tube after incubated for 15 mins. (E) The chemotactic ability of zoospores towards the root hair zone after incubated for $15 \mathrm{~min}$. (F) The rupture of spores near the root. Arrow in (F) shows the ruptured spores.

TABLE 1 | Influence of Phytophthora parasitica var. nicotianae cystospores with rapeseed roots.

\begin{tabular}{|c|c|c|c|}
\hline Treatments & $\begin{array}{c}\text { Cystospore } \\
\text { rupture rate }(\%)^{a}\end{array}$ & $\begin{array}{c}\text { Cystospore } \\
\text { germination rate }(\%)^{b}\end{array}$ & $\begin{array}{c}\text { Percentage of germ tube } \\
\text { growth towards the root }(\%)^{b}\end{array}$ \\
\hline Roots & $8.14 \pm 2.59^{* *}$ & $33.84 \pm 10.46^{* *}$ & $46.11 \pm 9.26^{* *}$ \\
\hline Capillary tube & $0.21 \pm 0.21$ & $1.56 \pm 0.79$ & $18.59 \pm 9.59$ \\
\hline
\end{tabular}

a The cystospore rupture rate was calculated at $30 \mathrm{~min}$ after zoospores exposure to root

b The cystospore germination rate and percentage of germ tube growth towards the root were recorded at 120 min after zoospores exposure to root.

Double asterisks $\left({ }^{* *}\right)$ indicate statistically significant differences (Student's t-test; $p<0.01 ; n=15$ ). 

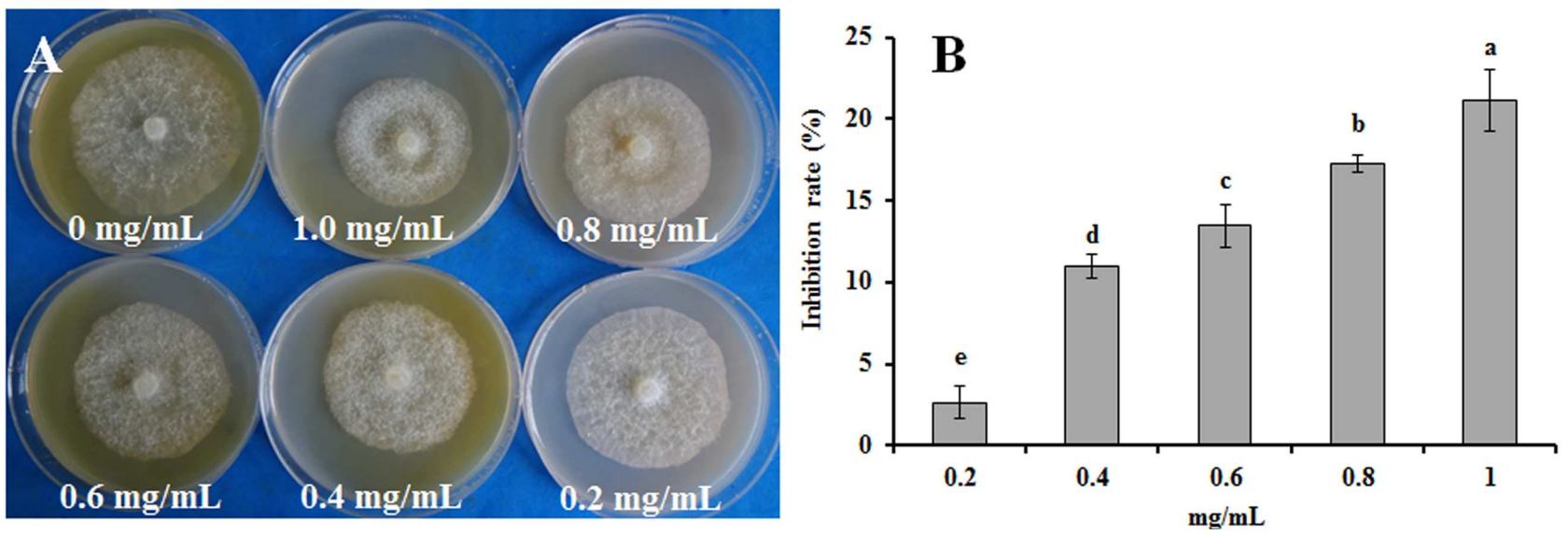

FIGURE 3 | (A) Effect of rapeseed root exudates on the mycelial growth of $P$. parasitica var. nicotianae. (B) Bars are the means \pm SE. Bars with different letters are significantly different $(p<0.05)$.

TABLE 2 | Compounds identified by GC-MS analysis in rapeseed root exudates.

\begin{tabular}{|c|c|c|c|c|c|c|}
\hline Group & Peak & Closest compound & Formula & Molecular weight & Characteristic fragments & $\begin{array}{c}\text { Spectra similarity } \\
(\%)^{\mathrm{a}}\end{array}$ \\
\hline \multirow[t]{6}{*}{ Acids } & 3 & 2-Butenoic acid & $\mathrm{C}_{4} \mathrm{H}_{6} \mathrm{O}_{2}$ & 86 & $86,69,57,53,49,45$ & 91 \\
\hline & 4 & Valeric acid & $\mathrm{C}_{5} \mathrm{H}_{10} \mathrm{O}_{2}$ & 102 & $73,60,55,45,43,42,41,39$ & 83 \\
\hline & 6 & 2-Pentenoic acid & $\mathrm{C}_{5} \mathrm{H}_{8} \mathrm{O}_{2}$ & 100 & $100,55,57,45,43,41,39$ & 90 \\
\hline & 15 & Nonanoic acid & $\mathrm{C}_{9} \mathrm{H}_{18} \mathrm{O}_{2}$ & 158 & $129,115,98,73,60,55$ & 80 \\
\hline & 22 & n-Hexadecanoic acid & $\mathrm{C}_{16} \mathrm{H}_{32} \mathrm{O}_{2}$ & 256 & $256,213,129,73,43$ & 98 \\
\hline & 21 & 9-Hexadecenoic acid & $\mathrm{C}_{16} \mathrm{H}_{30} \mathrm{O}_{2}$ & 254 & $254,236,97,83,69,55,41$ & 96 \\
\hline \multirow[t]{4}{*}{ Esters } & 2 & Methyl thiocyanate & $\mathrm{C}_{2} \mathrm{H}_{3} \mathrm{NS}$ & 73 & $73,58,49,47,45$ & 90 \\
\hline & 7 & Cyclohexyl isocyanate & $\mathrm{C}_{7} \mathrm{H}_{11} \mathrm{NO}$ & 125 & $125,97,82,67,41$ & 93 \\
\hline & 13 & Cyclohexyl isothiocyanate & $\mathrm{C}_{7} \mathrm{H}_{11} \mathrm{NS}$ & 141 & $141,83,55$ & 87 \\
\hline & 24 & Linoleic acid ethyl ester & $\mathrm{C}_{20} \mathrm{H}_{36} \mathrm{O}_{2}$ & 308 & $308,263,123,109,95,81,67,55,41$ & 99 \\
\hline \multirow[t]{2}{*}{ Ketones } & 5 & 2-Heptanone & $\mathrm{C}_{7} \mathrm{H}_{14} \mathrm{O}$ & 114 & $114,99,71,58,43,39$ & 80 \\
\hline & 14 & 1-(4-Ethylphenyl)-ethanone & $\mathrm{C}_{10} \mathrm{H}_{12} \mathrm{O}$ & 148 & $148,133,105$ & 97 \\
\hline \multirow[t]{2}{*}{ Aldehydes } & 1 & 3-Methyl butyraldehyde & $\mathrm{C}_{5} \mathrm{H}_{10} \mathrm{O}$ & 86 & $86,71,58,55,44,41,38$ & 86 \\
\hline & 10 & Nonanal & $\mathrm{C}_{9} \mathrm{H}_{18} \mathrm{O}$ & 142 & $124,119,98,82,57,41$ & 80 \\
\hline \multirow{3}{*}{$\begin{array}{l}\text { Nitrogen-containing } \\
\text { compounds }\end{array}$} & 12 & Benzothiazole & $\mathrm{C}_{7} \mathrm{H}_{5} \mathrm{NS}$ & 135 & $135,108,91$ & 83 \\
\hline & 19 & 2-(Methylthio)benzothiazole & $\mathrm{C}_{8} \mathrm{H}_{7} \mathrm{NS}_{2}$ & 181 & $181,148,136,108,69$ & 95 \\
\hline & 26 & 9-Octadecenamide & $\mathrm{C}_{18} \mathrm{H}_{35} \mathrm{NO}$ & 281 & $281,126,98,72,59,41$ & 99 \\
\hline \multirow[t]{8}{*}{ Alkanes } & 8 & Decane & $\mathrm{C}_{10} \mathrm{H}_{22}$ & 142 & $142,113,85,71,57,43$ & 94 \\
\hline & 9 & Undecane & $\mathrm{C}_{11} \mathrm{H}_{24}$ & 156 & $156,85,71,57,43,39$ & 90 \\
\hline & 11 & Dodecane & $\mathrm{C}_{12} \mathrm{H}_{26}$ & 170 & $170,85,71,57,43,39$ & 94 \\
\hline & 16 & Tetradecane & $\mathrm{C}_{14} \mathrm{H}_{30}$ & 198 & $198,155,85,71,57,43$ & 96 \\
\hline & 18 & Hexadecane & $\mathrm{C}_{16} \mathrm{H}_{34}$ & 226 & $226,85,71,57,43$ & 87 \\
\hline & 20 & Octadecane & $\mathrm{C}_{18} \mathrm{H}_{38}$ & 254 & $254,99,85,71,57,43$ & 98 \\
\hline & 23 & Eicosane & $\mathrm{C}_{20} \mathrm{H}_{42}$ & 282 & $282,99,85,71,57$ & 98 \\
\hline & 25 & 1-Docosene & $\mathrm{C}_{22} \mathrm{H}_{44}$ & 308 & $125,111,97,83,69,55,43$ & 99 \\
\hline Indoles & 17 & 4-Methoxyindole & $\mathrm{C}_{9} \mathrm{H}_{9} \mathrm{NO}$ & 147 & $147,132,104$ & 94 \\
\hline
\end{tabular}

a Spectra similarity compared with mass spectrum of the reference compounds stored in Wiley71.1 (\%).

which occurred within five minutes after the zoospores were exposed to the rapeseed root (Supplementary Table S2). After being attracted to the rapeseed root surface, the zoospores quickly stopped and encysted into the cystospores on the root surface or near the root (Figures 2B,C). Some cystospores on the rapeseed root tips even ruptured after $30 \mathrm{~min}$ (Table 1; Figure 2F). After $120 \mathrm{~min}$ incubation, $33.84 \%$ of cystospores germinated and $46.11 \%$ of the germ tubes grew toward the rapeseed roots, which was significantly higher than in the control treatment (Table 1). 

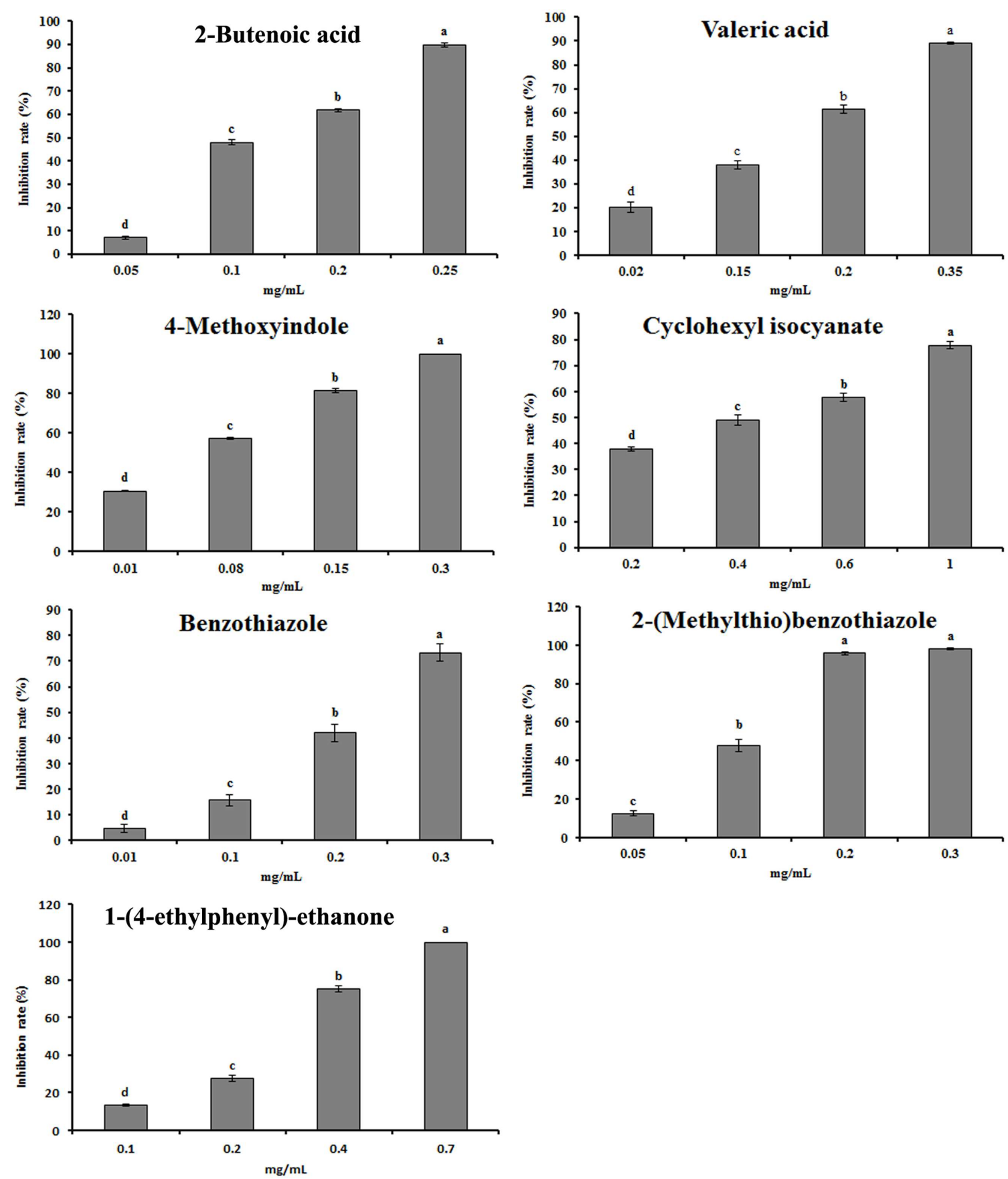

FIGURE 4 | Effect of the identified compounds in root exudates on the mycelial growth of $P$. parasitica var. nicotianae. Bars are the means \pm SE. Bars with different letters are significantly different $(p<0.05)$.

\section{Rapeseed Root Exudates Inhibit the Growth of $P$. parasitica var. nicotianae}

The rapeseed root exudates had dose-dependent antimicrobial activity against the mycelial growth of $P$. parasitica var. nicotianae (Figure 3). The inhibition rate reached $21.09 \%$ when mycelia were exposed to the root exudates at concentration of $1.0 \mathrm{mg} / \mathrm{mL}$ (Figure 3).

\section{Compound Identification in the Root Exudates}

Gas chromatography-mass spectrometry analysis identified a total of 26 putative compounds in the rapeseed root exudates (Supplementary Figure S1; Table 2), which were identified as 6 acids, 4 esters, 2 ketones, 2 aldehydes, 3 nitrogen-containing compounds, 
8 alkanes, and 1 indole based on their chemical nature.

\section{Inhibitory Activity Against $P$. parasitica var. nicotianae of the Compounds in the Root Exudates}

The antimicrobial activity of 14 compounds in the rapeseed root exudates was tested using pure compounds. Among these compounds, 2-butenoic acid, valeric acid, 4-methoxyindole, cyclohexyl isocyanate, benzothiazole, 2(methylthio)benzothiazole and 1-(4-ethylphenyl)-ethanone showed significant dose-dependent antimicrobial activity against the growth of mycelia (Figure 4). The $\mathrm{EC}_{50}$ values ranged from 27.46 to $366.37 \mathrm{mg} / \mathrm{L}$ (Supplementary Table S1). Other seven compounds, such as several alkanes and palmitic acid, did not have significant antimicrobial activity (Supplementary Table S1).

\section{Compound Concentrations in the Root Exudates and Their Antimicrobial Activities}

The concentrations of the above seven antimicrobial compounds in the rapeseed root exudates were further analyzed by HPLC. Only 2-butenoic acid, benzothiazole, 2(methylthio)benzothiazole, 1-(4-ethylphenyl)-ethanone, and 4methoxyindole were quantified by HPLC (Table 3; Supplementary Figure S2). The antimicrobial activity of these compounds against zoospore motility and cystospore germination of $P$. parasitica var. nicotianae was further tested based on their concentration in the root exudates. These five compounds exerted dose-respondent inhibitory effects on zoospore motility and cystospore germination (Figure 5). The $\mathrm{EC}_{50}$ values of these five compounds for zoospore motility and cystospore germination were $0.64-133.83$ and $3.28-523.96 \mathrm{mg} / \mathrm{L}$, respectively. All of these compounds showed high activity against zoospore motility compared with cystospore germination (Figure 5).

\section{DISCUSSION}

Tobacco monoculture leads to outbreaks of black shank in tobacco and decreased yields (Kong et al., 1995; Gallup et al., 2006). Our 4-year field experiment confirmed that rapeseed and tobacco rotation significantly suppressed black shank disease in tobacco. Many other studies also support the high potential for using rapeseed in rotation, cover, or green manure crops for the suppression of soil-borne diseases (Larkin and Griffin, 2007; Larkin et al., 2010). Reportedly, crop rotation can help reduce soil-borne pathogens, such as fungi, bacteria, Oomycetes, and nematodes, by (i) interrupting or breaking the host-pathogen cycle; (ii) altering the soil characteristics to make the soil environment less conducive for pathogen development or survival, often stimulating microbial activity and diversity or beneficial plant microbes; or (iii) directly inhibiting pathogens either through the production of inhibitory or toxic compounds in the roots or plant residues or the stimulation of specific microbial antagonists that directly suppress the pathogen inoculum (Larkin et al., 2010; Larkin, 2015).

In the present study, rapeseed root exudates play important role in the suppression of $P$. parasitica var. nicotianae. This pathogen is a typical soil-borne pathogen that infects plants through the production of zoospores, which involves a prepenetration process of zoospore taxis, encystment, cystospore germination, and orientation of the germ tube (Erwin and Ribeiro, 1996). We found that rapeseed roots could attract zoospores to their surface where they were encysted into cystospores. After the cystospores germinated, the growth of the germ tube also proceeded toward the roots. Some studies have indicated that the attraction of plant roots to zoospores was not host specific (Deacon, 1988). The chemotaxis and electrotaxis of zoospores toward plant roots are involved in the attraction of zoospores to host and non-host roots (Cameron and Carlile, 1978; Carlile, 1983; van West et al., 2002). After being attracted by the rapeseed roots, some of the spores could not germinate, and some spores even ruptured, which indicates that rapeseed roots can attract zoospores and hyphal growth and then secrete antimicrobial substances against the infection by the zoospores and hyphal growth.

Evidently, rapeseed root exudates showed dose-dependent antimicrobial activity against the mycelial growth of $P$. parasitica var. nicotianae. A library of antimicrobial compounds, including 2-butenoic acid, valeric acid, 4-methoxyindole, cyclohexyl isocyanate, benzothiazole, 2-(methylthio)benzothiazole and 1-(4-ethylphenyl)-ethanone, were further identified by GC-MS in the rapeseed root exudates. These compounds showed significant dose-dependent antimicrobial activity against zoospore motility, cystospore germination, and mycelia growth. Notably, 2-butenoic acid, benzothiazole, 2(methylthio)benzothiazole, 1-(4-ethylphenyl)-ethanone, and 4-methoxyindole showed antimicrobial activity against zoospore motility and cystospore germination at the concentrations detected in the rapeseed root exudates. Among these compounds, benzothiazole and 2-(methylthio)-benzothiazole have previously

TABLE 3 | Concentration of the target compounds in rapeseed root exudates from HPLC.

\begin{tabular}{lcr}
\hline Compound & Calibration curve & Concentration $(\boldsymbol{\mu} \mathbf{g} / \mathbf{m L}) \pm$ standard error (SE) \\
\hline 2-Butenoic acid & $Y=0.0206 x-6.8416, R^{2}=0.9971$ & $0.76 \pm 0.32$ \\
Benzothiazole & $Y=0.0122 x-2.2555, R^{2}=0.9997$ & $10.02 \pm 2.45$ \\
2-(Methylthio)benzothiazole & $Y=0.0240 x-1.3610, R^{2}=0.9999$ & $7.14 \pm 2.67$ \\
1-(4-ethylphenyl)-ethanone & $Y=0.0181+1.0301, R^{2}=0.9999$ & $2.18 \pm 0.97$ \\
4-Methoxyindole & $Y=0.0125 x-3.9263, R^{2}=0.9988$ & $56.54 \pm 10.28$
\end{tabular}



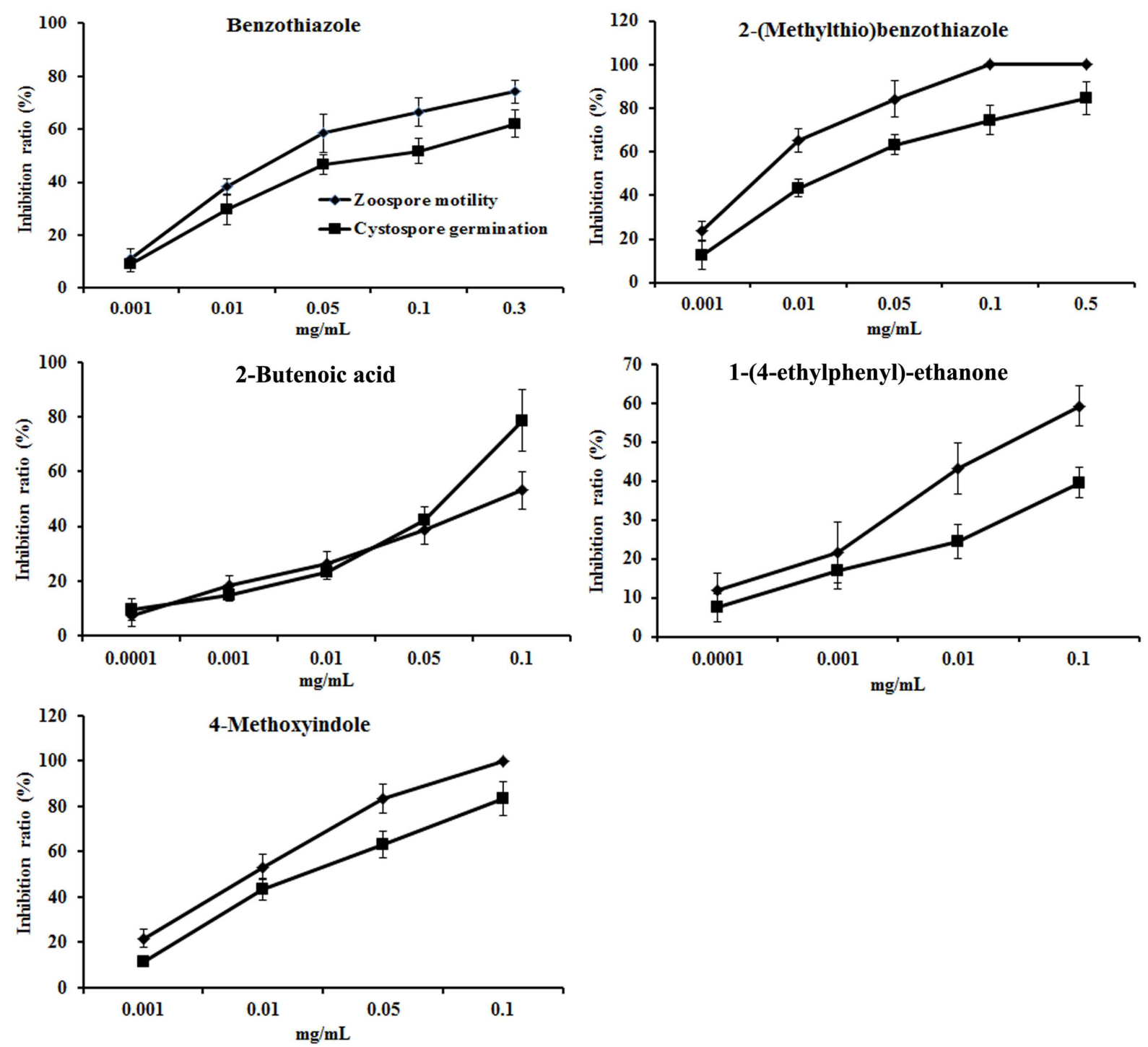

FIGURE 5 | The inhibitory activity of compounds against the motility of zoospores and the germination of cystospores. Error bars indicate the SE of three replicates.

been identified as antimicrobial compounds against some fungal and oomycete phytopathogens in the root exudates and volatiles of plants as well as in soil bacteria (Bjostard and Hibbard, 1992; Sun et al., 2003; Lane et al., 2004; He et al., 2005; Gaquerel et al., 2009; Hu et al., 2009; Yadav et al., 2011; Zhang et al., 2011; Xu et al., 2012; Yang et al., 2014). 2-Butenoic acid and valeric acid are important organic acids in plant root exudates and possess antimicrobial activity (Corsetti et al., 1998; Baudoin et al., 2003; Sandnes et al., 2005). 1-(4-ethylphenyl)ethanone exhibited antimycobacterial activity (Rajabi et al., 2005), and 4-methoxyindole and other indole derivatives have been reported in root exudates with antimicrobial activity (Seal et al., 2004; Paudel et al., 2012; Wu and Chen, 2015). The Brassicaceae family produces sulfur compounds that break down to produce isothiocyanates that are toxic to many soil organisms (Sarwar et al., 1998). In this study, cyclohexyl isocyanate was identified in the root exudates and showed antimicrobial activity. Although the antimicrobial activity of these compounds in rapeseed root exudates was identified, the secretion mechanism of these compounds from root tissue and their mode of action against $P$. parasitica var. nicotianae are still unknown.

The above data demonstrated that rapeseed can secrete many antimicrobial compounds through its root exudates to kill soilborne pathogens. Plants are a primary driver of changes in soil microbial communities, and recent studies have documented that crop rotations can dramatically affect these communities (Lupawayi et al., 1998; O’Donnell et al., 2001; Larkin, 2003, 2008; Sturz and Christie, 2003; Larkin and Griffin, 2007; Van Elsas and Costa, 2007; Larkin et al., 2010; Chaparro et al., 2012) 
and stimulate specific microbial antagonists that directly suppress pathogen inocula (Mazzola et al., 2001; Garbeva et al., 2004; Welbaum et al., 2004). Brassica crops rotated with potato had higher microbial activity and diversity, which may help to suppress soil-borne diseases potatoes (Garbeva et al., 2004; Welbaum et al., 2004; Ghorbani et al., 2008; Larkin, 2008). Thus, whether rotating rapeseed with tobacco increases the soil microbial activity and diversity, the populations of plantbeneficial organisms, and the antagonism toward pathogens to result in disease suppression is interesting and should be evaluated further.

\section{CONCLUSION}

Rapeseed rotated with tobacco can effectively suppress black shank disease of tobacco caused by $P$. parasitica var. nicotianae in the field. Rapeseed roots can attract zoospores into the rhizosphere and then secrete a series of antimicrobial substances to kill them, which eventually caused $P$. parasitica var. nicotianae to lose its ability to spread or survive in the soil.

\section{REFERENCES}

Bais, H. P., Park, S. W., Weir, T. L., Callaway, R. M., and Vivanco, J. M. (2004). How plants communicate using the underground information superhighway. Trends Plant Sci. 9, 26-32. doi: 10.1016/j.tplants.2003.11.008

Bais, H. P., Weir, T. L., Perry, L. G., Gilroy, S., and Vivanco, J. M. (2006). The role of root exudates in rhizosphere interactions with plants and other. Annu. Rev. Plant Biol. 57, 233-266. doi: 10.1146/annurev.arplant.57.032905.105159

Baudoin, E., Benizri, E., and Guckert, A. (2003). Impact of artificial root exudates on the bacterial community structure in bulk soil and maize rhizosphere. Soil Biol. Biochem. 35, 1183-1192. doi: 10.1016/S0038-0717(03)00179-2

Bjostard, L. B., and Hibbard, B. E. (1992). 6-Methoxy-2-benzoxazotinone: a semiochemical for host location by Western corn root worm larvae. J. Chem. Ecol. 18, 931-944. doi: 10.1007/BF00980054

Brown, P. D., and Morra, M. J. (1997). Control of soilborne plant pests using glucosinolate containing plants. Adv. Agron. 61, 167-231. doi: 10.1016/S00652113(08)60664-1

Cameron, J. N., and Carlile, M. J. (1978). Fatty acids, aldehydes and alcohols as attractants for zoospores of Phytophthora palmivora. Nature 271, 448-449. doi: $10.1038 / 271448 \mathrm{a} 0$

Carlile, M. J. (1983). "Motility, taxis and tropism in Phytophthora," in Phytophthora: Its Biology, Taxonomy, Ecology and Pathology, eds D. C. Erwin, S. Bartnicki-Garcia, and P. H. Tsao (St. Paul, MA: APS Press), 95-107.

Chaparro, J. M., Sheflin, A. M., Manter, D. K., and Vivanco, J. M. (2012). Manipulating the soil microbiome to increase soil health and plant fertility. Biol. Fertil. Soils 48, 489-499. doi: 10.1007/s00374-012-0691-4

Cohen, M. F., Mazzola, M., and Yamasaki, H. (2005). Brassica napus seed meal soil amendment modifies microbial community structure, nitric oxide production and incidence of Rhizoctonia root rot. Soil Biol. Biochem. 37, 1215-1227. doi: 10.1016/j.soilbio.2004.11.027

Corsetti, A., Gobbetti, M., Rossi, J., and Damiani, P. (1998). Antimould activity of sourdough lactic acid bacteria: identification of a mixture of organic acids produced by Lactobacillus sanfrancisco CB1. Appl. Microbiol. Biotechnol. 50, 253-256. doi: 10.1007/s002530051285

Deacon, J. W. (1988). Behavioural responses of fungal zoospores. Microbiol. Sci. 5, 249-252.

Erwin, D. C., and Ribeiro, O. K. (1996). "Phytophthora capsici," in Phytophthora Diseases Worldwide, eds D. C. Erwin and O. K. Ribeiro (St. Paul, MN: APS Press), 262-268.

Gallup, C. A., Sullivan, M. J., and Shew, H. D. (2006). Black shank of tobacco. Plant Health Instruct. doi: 10.1094/PHI-I-2006-0717-01

\section{AUTHOR CONTRIBUTIONS}

SZ, LZ and MY designed the research; YF, YJ, JL, LL, and JL performed the research; KD, SJ, and LZ analyzed the data; SZ and MY wrote the paper; LZ, YJ and SJ reviewed the paper.

\section{ACKNOWLEDGMENTS}

This project was supported by the science and technology plan of tobacco in Yunnan Province (2012YN42) and the National Science Foundation of China (31260447). The funders had no role in study design, data collection and analysis, decision to publish, or preparation of the manuscript.

\section{SUPPLEMENTARY MATERIAL}

The Supplementary Material for this article can be found online at: http://journal.frontiersin.org/article/10.3389/fmicb. 2016.00894

Gaquerel, E., Weinhold, A., and Baldwin, I. T. (2009). Molecular interactions between the specialist herbivore Manduca sexta (Lepidoptera, Sphigidae) and its natural host Nicotiana attenuata. VIII. An unbiased GC6GC-ToFMS analysis of the plant's elicited volatile emissions. Plant Physiol. 149, 1408-1423. doi: 10.1104/pp.106.088781

Garbeva, P., van Veen, J. A., and van Elsas, J. D. (2004). Microbial diversity in soil: selection of microbial populations by plant and soil type and implications for disease suppressiveness. Annu. Rev. Phytopathol. 42, 243-270. doi: 10.1146/annurev.phyto.42.012604.135455

Ghorbani, R., Wilockson, S., Koocheki, A., and Leifert, C. (2008). Soil management for sustainable crop disease control: a review. Environ. Chem. Lett. 6, 149-162. doi: 10.1007/s10311-008-0147-0

He, H. B., Chen, X. X., Lin, R. X., Lin, W. X., He, H. Q., Jia, X. L., et al. (2005). Chemical components of root exudates from allelopathic rice accession PI312777 seedlings, Chinese. J. Appl. Ecol. 16, 2383-2388. doi: 10.13287/j.10019332.2005.0356

Hu, Z. H., Shen, Y. B., Shen, F. Y., Luo, Y. Q., and Su, X. H. (2009). Evidence for the signaling role of methyl jasmonate, methyl salicylate and benzothiazole between poplar (Populus simonii 6P. pyramidalis 'Opera 8277') cuttings. Trees 23, 1003-1011. doi: 10.1007/s00468-009-0342-z

Kheyrodin, H. (2011). Crop rotations for managing soil-borne plant diseases. Afr. J. Food Sci. Technol. 2, 1-9.

Kong, F., Zhu, X., Shi, J., and Guo, Z. (1995). Developing tendency causes and control measures of tobacco infectious diseases in China. China Tobacco 16, 31-34. doi: 10.13496/j.issn.1007-5119.1995.01.008

Lane, N., Weidenhamer, J. D., and Romeo, J. T. (2004). Zapoteca formosa: sulfur chemistry and phytotoxicity. J. Chem. Ecol. 30, 425-437. doi: 10.1023/B:JOEC.0000017986.49513.f7

Larkin, R. P. (2003). Characterization of soil microbial communities under different potato cropping systems by microbial population dynamics, substrate utilization, and fatty acid profiles. Soil Biol. Biochem. 35, 1451-1466. doi: 10.1094/PHYTO-04-10-0100

Larkin, R. P. (2008). Relative effects of biological amendments and crop rotations on soil microbial communities and soilborne diseases of potato. Soil Biol. Biochem. 40, 1341-1351. doi: 10.1016/j.soilbio.2007.03.005

Larkin, R. P. (2015). Soil health paradigms and implications for disease management. Annu. Rev. Phytopathol. 53, 199-221. doi: 10.1146/annurevphyto-080614-120357

Larkin, R. P., and Griffin, T. S. (2007). Control of soilborne diseases of potato using Brassica green manures. Crop Protect. 26, 1067-1077. doi: 10.1016/j.cropro.2006.10.004 
Larkin, R. P., Griffin, T. S., and Honeycutt, C. W. (2010). Rotation and cover crop effects on soilborne potato diseases, tuber yield, and soil microbial communities. Plant Dis. 94, 1491-1502. doi: 10.1094/PDIS-03-10-0172

Li, T., Wang, B., and Wang, S. (2006). The current situations, problems and measures of tobacco in Yunnan. Chinese Tobacco Sci. 27, 48-51. doi: 10.13496/j.issn.1007-5119.2006.02.015

Lupawayi, N. Z., Rice, W. A., and Clayton, G. W. (1998). Soil microbial diversity and community structure under wheat as influenced by tillage and crop rotation. Soil Biol. Biochem. 30, 1733-1741. doi: 10.1016/S0038-0717(98) 00025-X

Matthiessen, J. N., and Kirkegaard, J. A. (2006). Biofumigation and enhanced biodegradation: opportunity and challenge in soilborne pest and disease management. Crit. Rev. Plant Sci. 25, 235-265. doi: 10.1080/07352680600611543

Mazzola, M., Granatstein, D. M., Elfving, D. C., and Mullinix, K. (2001). Suppression of specific apple root pathogens by Brassica napus seed meal amendment regardless of glucosinolate content. Phytopathology 91, 673-679. doi: 10.1094/PHYTO.2001.91.7.673

McGuire, A. N. (2003). Mustard green manures replace fumigant and improve infiltration in potato cropping system. Crop Manag. 2. doi: 10.1094/CM-20030822-01-RS

Morris, P. F., and Ward, E. W. B. (1992). Chemoattraction of zoospores of the soybean pathogen, Phytophthora sojae, by isoflavones. Physiol. Mol. Plant Pathol. 40, 17-22. doi: 10.1016/0885-5765(92)90067-6

Muehlstein, L. K., Amon, J. P., and Leffler, D. L. (1988). Chemotaxis in the marine fungus Rhizophydium littoreum. Appl. Environ. Microbiol. 54, 1668-1672.

O’Donnell, A. G., Seasman, M., MacRae, A., Waite, I., and Davies, J. T. (2001). Plants and fertilizers as drivers of change in microbial community structure and function in soils. Plant Soil 232, 135-145. doi: 10.1023/A:1010394221729

Paudel, A., Hamamoto, H., Kobayashi, Y., Yokoshima, S., Fukuyama, T., and Sekimizu, K. (2012). Identification of novel deoxyribofuranosyl indole antimicrobial agents. J. Antibiot. 65, 53-57. doi: 10.1038/ja.2011.110

Rajabi, L., Courreges, C., Montoya, J., Aguilera, R. J., and Primm, T. P. (2005). Acetophenones with selective antimycobacterial activity. Lett. Appl. Microbiol. 40, 212-217. doi: 10.1111/j.1472-765X.2005.01657.x

Ratnadass, A., Fernandes, P., Avelino, J., and Habib, R. (2012). Plant species diversity for sustainable management of crop pests and diseases in agroecosystems: a review. Agron. Sustain. Dev. 32, 273-303. doi: 10.1007/s13593-011-0022-4

Sandnes, A., Eldhuset, T. D., and Wollebaek, G. (2005). Organic acids in root exudates and soil solution of Norway spruce and silver birch. Soil Biol. Biochem. 37, 259-269. doi: 10.1016/j.soilbio.2004.07.036

Sarwar, M., Kirkegaard, J. A., Wong, P. T. W., and Desmarchelier, J. M. (1998). Biofumigation potential of brassicas. III. In vitro toxicity of isothiocyanates to soil-borne fungal pathogens. Plant Soil 210, 103-112. doi: 10.1023/A:1004381129991

Seal, A. N., Pratley, J. E., Haig, T., and An, M. (2004). Identification and quantitation of compounds in a series of allelopathic and nonallelopathic rice root exudates. J. Chem. Ecol. 30, 1647-1662. doi: 10.1023/B:JOEC.0000042074.96036.14

Smolinska, U., and Horbowicz, M. (1999). Fungicidal activity of volatiles from selected cruciferous plants against resting propagules of soil-borne fungal pathogens. J. Phytopathol. 147, 119-124. doi: 10.1046/j.1439-0434.1999.147002119.x

Sturz, A. V., and Christie, B. R. (2003). Beneficial microbial allelopathies in the root zone: the management of soil quality and plant disease with rhizobacteria. Soil Tillage Res. 72, 107-123. doi: 10.1016/S0167-1987(03)00082-5
Sullivan, M. J., Melton, T. A., and Shew, H. D. (2005). Managing the race structure of Phytophthora parasitica var. nicotianae with cultivar rotation. Plant Dis. 89, 1285-1294. doi: 10.1094/PD-89-1285

Sun, H. Y., Wang, Y. Z., and Yang, L. (2003). Analysis of the major components of root exudates released from several economic forest tree using GC-MS. J. For. Res. 14, 127-129. doi: 10.1007/BF02856778

Sun, J., Li, X., Wu, Z., and Sun, H. (2011). Progress on tobacco black shank disease. Hubei Agric. Sci. 50, 3253-3255. doi: 10.14088/j.cnki.issn0439-8114.2011. 16.030

Van Elsas, J. D., and Costa, R. (2007). "Molecular assessment of soil microbial communities with potential for plant disease suppression," in Biotechnology and Plant Disease Management, eds Z. K. Punja, S. H. Boer, and H. Sanfacon (King's Lynn: CABI), 498-517.

van West, P., Morris, B. M., Reid, B., Appiah, A., Osborne, M. C., Campbell, T. A., et al. (2002). Oomycete plant pathogens use electric fields to target roots. Mol. Plant Microbe Interact 15, 790-798. doi: 10.1094/MPMI.2002.15.8.790

Welbaum, G. E., Sturz, A. V., Dong, Z., and Nowak, J. (2004). Managing soil microorganisms to improve productivity of agroecosystems. Crit. Rev. Plant Sci. 23, 175-193. doi: 10.1080/07352680490433295

Wu, Y., and Chen, G. (2015). Progress of the antimicrobial activities of indole-2,3-dione derivatives. Chem. Reagents 37, 702-706. doi: 10.13822/j.cnki.hxsj.2015.08.007

Xu, N., Wang, C., Wei, M., Shi, W., and Wang, X. F. (2012). Allelopathy of Welsh onion root exudates on cucumber seed germination and Fusarium oxysporum f. sp. cucumerinum and the GC-MS analysis. Acta Hortic. Sin. 39, 1511-1520.

Yadav, P. S., Devprakash, and Senthilkumar, G. P. (2011). Benzothiazole: different methods of synthesis and diverse biological activities. Int. J. Pharm. Sci. Drug Res. 3, 1-7. doi: 10.1002/chin.201140238

Yang, M., Zhang, Y., Qi, L., Mei, X., Liao, J., Ding, X., et al. (2014). Plant-plant-microbe mechanisms involved in soil-borne disease suppression on a maize and pepper intercropping system. PLOS ONE 9:e115052. doi: 10.1371/journal.pone.0115052

Zhang, L., Fang, Y., Ji, S., Jiao, Y., Liao, J., Li, J., et al. (2015). Inhibitory activity of maize root exudates against Phytophthora nicotianae and antifungal compounds analysis. Chinese J. Biol. Control 31, 115-122. doi: 10.16409/j.cnki.2095-039x.2015.01.016

Zhang, S. H., Sun, P. S., Ge, F. J., and Wu, Z. B. (2011). Different sensitivities of Selenastrum capricornutum and toxic strain Microcystis aeruginosa to exudates from two Potamogeton species. Polish J. Environ. Stud. 20, 1359-1366.

Zhu, S. S., Liu, X. L., Liu, P. F., Li, J. Q., Wang, H. M., Yuan, S. K., et al. (2007). Flumorph is a novel fungicide that disrupts microfilament organization in Phytophthora melonis. Phytopathology 97, 643-649. doi: 10.1094/PHYTO-975-0643

Conflict of Interest Statement: The authors declare that the research was conducted in the absence of any commercial or financial relationships that could be construed as a potential conflict of interest.

Copyright (c) 2016 Fang, Zhang, Jiao, Liao, Luo, Ji, Li, Dai, Zhu and Yang. This is an open-access article distributed under the terms of the Creative Commons Attribution License (CC BY). The use, distribution or reproduction in other forums is permitted, provided the original author(s) or licensor are credited and that the original publication in this journal is cited, in accordance with accepted academic practice. No use, distribution or reproduction is permitted which does not comply with these terms. 